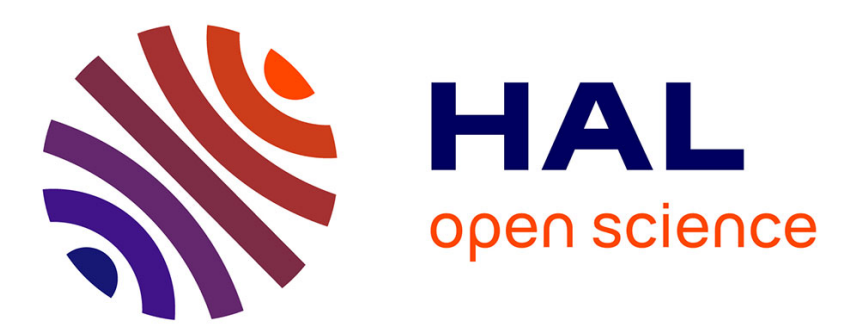

\title{
Radar analysis of a tropical convective boundary layer with shallow cumulus clouds \\ Laurence Eymard
}

\section{To cite this version:}

Laurence Eymard. Radar analysis of a tropical convective boundary layer with shallow cumulus clouds. Journal of the Atmospheric Sciences, 1984, 41 (8), pp.1380-1393. 10.1175/15200469(1984)0412.0.CO;2 . hal-01101813

\section{HAL Id: hal-01101813 https://hal.sorbonne-universite.fr/hal-01101813}

Submitted on 23 Jan 2015

HAL is a multi-disciplinary open access archive for the deposit and dissemination of scientific research documents, whether they are published or not. The documents may come from teaching and research institutions in France or abroad, or from public or private research centers.
L'archive ouverte pluridisciplinaire HAL, est destinée au dépôt et à la diffusion de documents scientifiques de niveau recherche, publiés ou non, émanant des établissements d'enseignement et de recherche français ou étrangers, des laboratoires publics ou privés. 


\title{
Radar Analysis of a Tropical Convective Boundary Layer with Shallow Cumulus Clouds
}

\author{
LAURENCE EYMARD \\ C.N.E.T./C.N.R.S./C.R.P.E., 9213I-Issy-Les-Moulineaux, France
}

(Manuscript received 15 August 1983, in final form 3 January 1984)

\begin{abstract}
A situation of fair weather cloudy convection is examined using a dual Doppler radar, environmental measurements and cloud photogrammetry. The convective layer is characterized by the interaction between the northward monsoon wind at low levels and the easterly wind above; a convective organization is found to be related to the shear between both flows. Moreover, at the convective scale, properties of the convective layer below clouds and in clear air are considered. They show significant differences in buoyancy and entrainment effects but similar effects of the shear on variances and momentum production profiles.
\end{abstract}

\section{Introduction}

One of the fundamental aspects of the atmospheric boundary layer is its interaction with nonprecipitating cumuli-the fair weather cloudy convection. Its structure includes interactions between different scales, from small-scale turbulence below and inside clouds to mesoscale organization (into cloud streets, for example).

Most of the studies consider this phenomenon from a local point of view, assuming horizontal homogeneity. Thus, one-dimensional models were developed by Manton (1981), Emanuel (1981), Ryan and Lalousis (1978), Asai and Kasahara (1966), Betts (1975, 1976) and Deardorff (1979), principally for determining vertical energy transports by buoyancy, shear, advection effects, and the mean evolution of the cloudy boundary layer. Indeed, these transports are of primary importance in understanding mesoscale evolution of the atmosphere, and in deep convection initiation. Experimental works were performed using instrumented tethered balloon (Kitchen and Caughey, 1981) or aircraft [Caughey and Readings (1974), Nicholls and LeMone (1980), Jensen and Lenshow (1978)]. Their purpose was essentially to determine vertical energy transports, or the kinetic energy budget in case of cloudy convection.

However, a spatial point of view was considered by LeMone (1973), studying the convective organization below cloud streets and by Kitchen and Caughey (1981) who looked at the flow circulation around small cumuli. Deardorff (1973) and Sommeria and Deardorff (1977) developed a three-dimensional model of convection for examining its dynamic and thermodynamic evolution.

The experimental spatial works using aircraft or balloons provide data in only one or two horizontal directions at just a few height levels. On the contrary,
Doppler radars record the spatial wind field over several kilometers horizontally in a short duration $(\sim 4 \mathrm{~min})$, with a better vertical resolution ( $100 \mathrm{~m}$, for example). The interest of radar observations in the boundary layer has been shown by several authors: Frisch $e t$ al. (1976) compared radar measurements with other instruments; Reinking et al. (1981) studied roll vortices; Kropfli and Kohn (1978) showed the effect of a thermal heterogeneity on the convective organization; Eymard and Weill (1982) also studied organized convective structures; Rabin and Zrnic' (1980) and Rabin et al. (1982) considered the air properties at larger scale (subsynoptic scale), in particular, calculating momentum fluxes. However, except in the last study, radars were never used for determining fluxes as well as for studying the cloudy convection in the boundary layer.

The purpose of the present study is to examine both dynamic organizations of the cloud and subcloud layers, and the circulation and transports associated with convection below clouds, compared with those of clear air areas.

Data from the two C-band Doppler radars (RONSARD system) of CRPE' (Nutten et al., 1979) are principally used, completed by measurements from a surface network, soundings of wind and temperature and photogrammetry of clouds. They were obtained during the COPT 81 (COnvection Profonde Tropicale) experiment performed in May and June 1981 in the Ivory Coast.

After describing the experimental processing, the first sections will consider the averages in the subcloud and cloud layers over the radar domain to determine their structure and organization. Properties of areas

\footnotetext{
' Centre de Recherches en Physique de l'Environnement.
} 


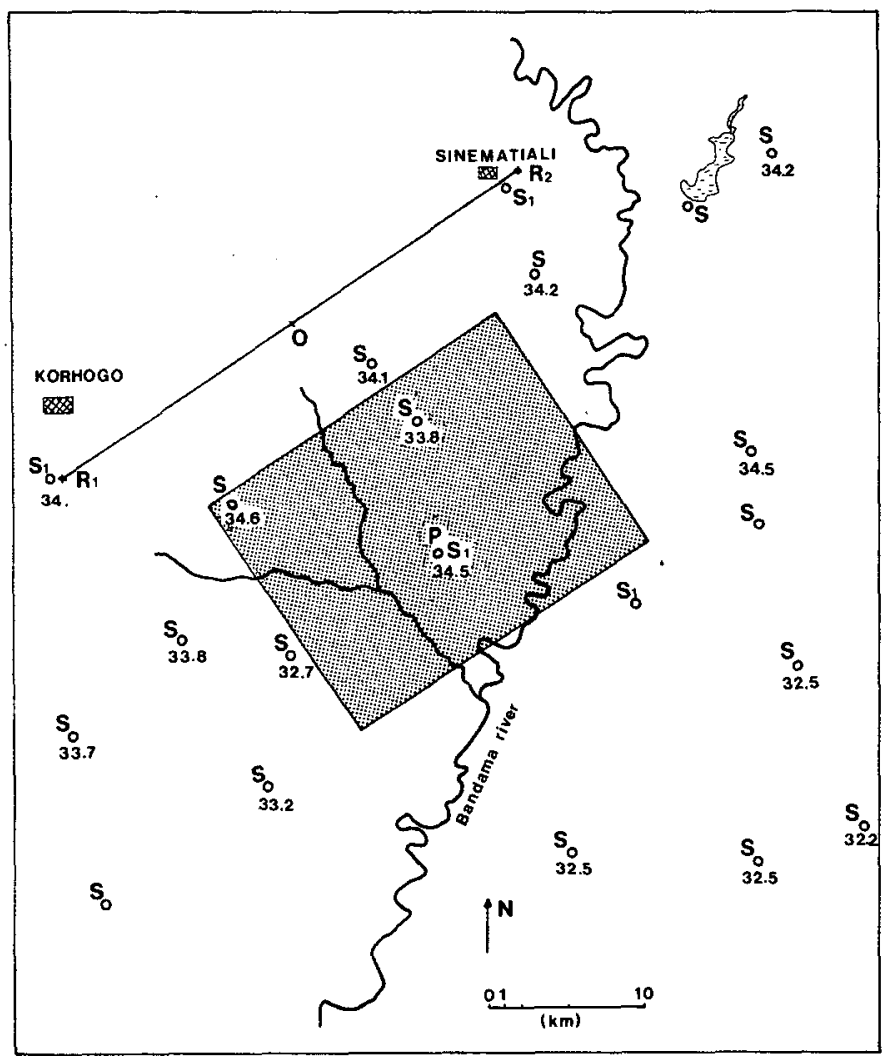

FIG. 1. Map of the experimental area, showing the principal cities and rivers and the instrument locations. Half-hour mean temperatures between 1530 and 1600 GMT are indicated at surface stations where they are available.

below clouds compared with clear air areas are the subject of the following section. Results concerning divergence, vorticity, velocity variances and momentum fluxes will also be presented.

\section{Experimental setting and radar methodology}

The COPT 81 experiment was conducted in the Ivory Coast at about latitude $10^{\circ} \mathrm{N}$, during May and June, 1981. Its principal purpose was the observation of isolated storms and squall lines frequently occurring at the beginning of the rainy season. The experiment has been described by Sommeria (1982), so we will describe only the instrumental setting involved in the boundary layer experiment.

Figure 1 shows the experimental area. The topography of the country is basically a plateau of mean altitude $330 \mathrm{~m}$. The highest zone is near point $P(380$ $\mathrm{m})$ and the altitude gently decreases to the Bandama river valley $(280 \mathrm{~m})$. The vegetation across the area comprises a patchy savanna and fields around villages. The following features should be noted.

- Two Doppler radars were employed, one located at each of the points R1 and R2. They explored the volume of a horizontal base represented by the shaded rectangle $(20 \mathrm{~km} \times 15 \mathrm{~km})$ in which chaff was released from an aircraft at a height of $600 \mathrm{~m}$.

- A surface network developed partly by EERM, ${ }^{2}$ and partly by LAMP, ${ }^{3}$ was composed of 22 meteorological stations $(\mathbf{S})$. They provided every few minutes $(\sim 3 \mathrm{~min})$ surface pressure, temperature, humidity, net radiation and wind speed and direction. At several stations ( $\mathrm{S}$ ), sensible and latent heat fluxes were also determined. A three-antenna Doppler sodar from CRPE was located near the R2 radar at Sinematiali.

- Wind and temperature soundings were performed near the R1 radar at Korhogo at the beginning and the end of each experiment and every day at 0600 and 1800 (all times GMT).

- Photogrammetry of clouds was realized by IOPG $^{4}$ near point P. Cloud sizes and locations were determined through a circular area of radius about $12 \mathrm{~km}$ around $\mathrm{P}$ during the experiment.

\footnotetext{
${ }^{2}$ Etablissement d'Etudes et de Recherches Météorologiques.

${ }^{3}$ Laboratoire Associé de Météorologie Physique.

${ }^{4}$ Institut de l'Observatoire de Physique du Globe.
} 
On 6 June 1981 an experiment was carried out between 1525 and 1630 . Soundings were performed at 1430 and 1715 and photogrammetry of clouds between 1535 and 1710 .

The dual-Doppler radars were operated following the coplane methodology (Miller and Strauch, 1974). The radar data are obtained between altitudes of 0.15 and $2 \mathrm{~km}$ according to the chaff diffusion. The total scanning time ranged from 210 to $280 \mathrm{~s}$. Three-dimensional wind fields from radar data [Testud and Chong (1983); Chong et al. (1983); Chong and Testud (1983)] have been recovered with a grid resolution $300-500 \mathrm{~m}$ horizontally and 100 or $150 \mathrm{~m}$ vertically. The accuracy in horizontal and vertical velocity components is $0.1-0.15 \mathrm{~m} \mathrm{~s}^{-1}$ and $0.2-0.25 \mathrm{~m} \mathrm{~s}^{-1}$, respectively, increasing with the distance from the radar baseline. The quality of the restored wind field depends on several factors, principally, the chaff density in the lowest elevation coplane and the flow stationarity.

The stationarity has been verified using correlation between successive sequences. (Eymard and Weill, 1982). Nevertheless, there was an important improvement between the two studies: Chong and Testud (1983) developed a variational analysis scheme to optimize the vertical velocity calculation by adjusting the boundary condition at ground level in order to improve the mathematical regularity of the vertical velocity field. Its effect is to uniformly distribute the instrumental noise with height. It is therefore possible to quantitatively study the vertical velocity properties, contrary to our previous work.

\section{Mean behavior of the subcloud layer and the cloud layer}

\section{a. Synoptic situation}

The incursion of the African monsoon during May and June is characterized by the interaction between the wet southerly monsoon flow with the easterly wind above it. The most important effect of this interaction is the frequent occurrence of thunderstorms (local thunderstorms or squall lines).

The boundary layer generally extends through the monsoon layer, capped by an inversion at the transition level. However, on 6 June 1981, the temperature and wind profiles show a more complex situation (Figs. 2 and 3): the monsoon wind blows toward the north with a speed $\sim 3 \mathrm{~m} \mathrm{~s}^{-1}$ from the surface up to a height of $1 \mathrm{~km}$. Higher, the easterly wind flows toward the southwest $\left(60^{\circ}\right.$ from south) above a rotating shear. The temperature sounding indicates an inversion layer at a height of $1.6 \mathrm{~km}$ at 1715 which caps the wellmixed layer extending through the monsoon layer and the base of the easterly flow. The condensation level is found near $1.7 \mathrm{~km}$, above the inversion level. Thus, the cumulus clouds do not occur inside the monsoon layer, but in the easterly flow, contrary to general observations during BOMEX and GATE experiments [Betts (1975); Nicholls and LeMone (1980)] and observations on the other days during the COPT 81 experiment.

Observations took place during the decreasing part of the surface heat flux (Fig. 4), maximum near 1500 .

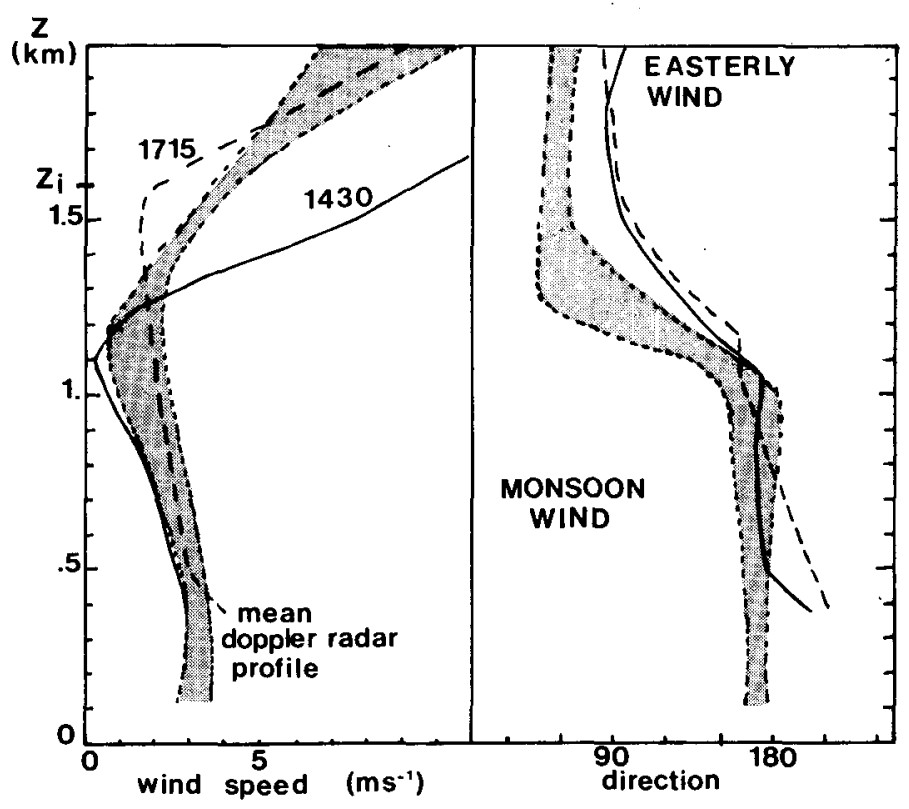

FIG. 2. Horizontal wind profiles from wind soundings at 1430 and 1715 GMT and Doppler radars (the shaded area is the envelope of 11 successive profiles). Directions are referred to south. The inversion height $Z_{i}$ at 1715 is indicated. 


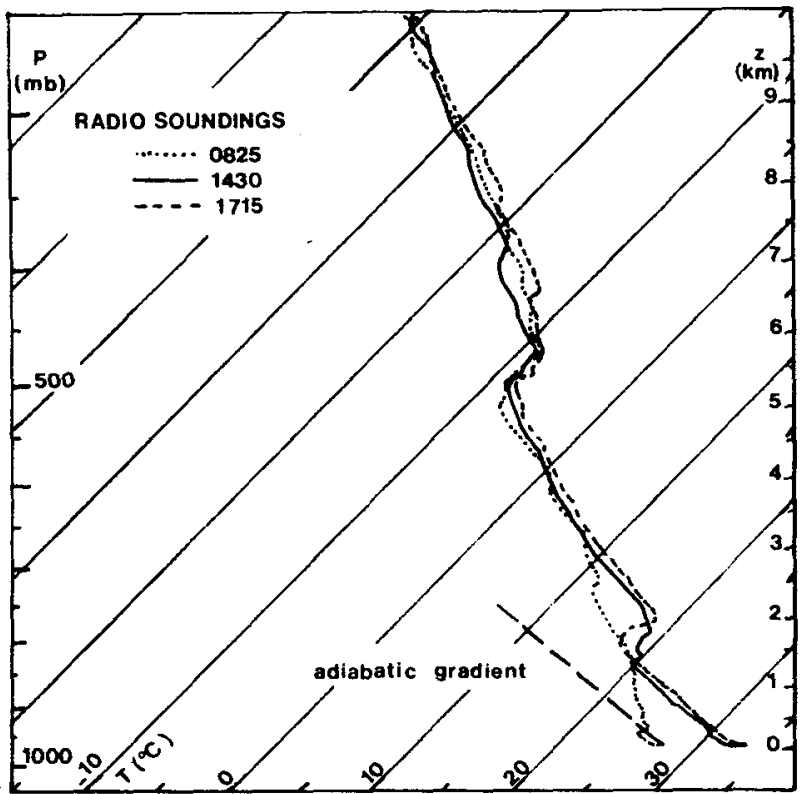

FIG. 3. Temperature soundings on 6 June 1981 at 0825,1430 and 1715 at Korhogo. The dry adiabatic gradient is indicated.

Temperature and humidity are near constant at their extreme values of $34^{\circ} \mathrm{C}$ and $62 \%$ respectively, and this period also corresponds to a decreasing number of clouds. After 1630, the humidity again increases and a thunderstorm was observed near 2100 .

\section{b. Convective layer dynamic properties}

The mean dynamic properties during the experiment are deduced from 11 recorded scans. The horizontal wind field is illustrated by Fig. 5 , at heights of $0.3,1.2$ and $1.5 \mathrm{~km}$ (the horizontal frame corresponds to the shaded rectangle in Fig. 1). At 1625, the wind field presents the same features as previously: the monsoon wind at $0.3 \mathrm{~km}$ is northward but the local wind direction varies by $90^{\circ}$ from place to place (this heterogeneity is also found near the surface, as shown by the surface network). At a height of $1.2 \mathrm{~km}$, the mean wind profile of Fig. 2 indicates a weak mean wind rotating with height. But the wind field exhibits wind fluctuations of intensity $1-5 \mathrm{~m} \mathrm{~s}^{-1}$ in different directions: there is not a regular wind rotation at this height. Above the shear, the wind is regular, blowing southwestward. It is only affected by some strong convective cells.

Thus, the convective layer is divided into two layers separated by a transition layer. Remembering this structure, we will examine the velocity variances and convective spatial organization.

\section{1) VelocitY VARIANCES}

The velocity variances are taken as spatial averages on the whole horizontal radar domain at each height level. Although they have been calculated at all sequences, we will only consider the six sequences with the best horizontal resolution, $300 \mathrm{~m}$. The corresponding vertical and horizontal velocity variance profiles are drawn in Fig. 6.

Below a height of $1 \mathrm{~km}$, the vertical variance presents a weak maximum at $0.45 \mathrm{~km}$ and then a slow decrease. This shape is in agreement with those observed by Kaimal et al. (1976) and Caughey and Palmer (1979), but the maximum is smaller: about $0.3 w_{*}^{2}$ instead of $0.4-0.5 w_{*}^{2}\left(w_{*}=1.5 \mathrm{~m} \mathrm{~s}^{-1}\right.$ deduced from the surface heat flux measured near $P$ ). This difference is essentially due to the small-scale filtering, but the different kinds of averaging (spatial and temporal) may have an influence. Between 1 and $1.5 \mathrm{~km}$, the vertical variance increases with height, because of shear production. Above $1.5 \mathrm{~km}$, entrainment is a possible cause of increasing, but also possibly radiative effects or latent heat release, as showed by Brost et al. (1982).

Horizontal variances are taken with respect to the mean spatial wind over the radar domain at every level, $u$ being alongwind and $v$ crosswind. They present large values $\left(u^{\prime 2} \approx 0.4 w_{*}^{2}\right.$ and $\left.v^{\prime 2} \approx 0.8 w_{*}^{2}\right)$ near the surface when compared with Caughey and Palmer's (1979) observations. This difference may be due to the horizontal heterogeneity or mesosynoptic disturbances, as noticed by Panofsky (1973) and Caughey and Palmer (1979), or to convective organization. Variances decrease weakly with height near $0.7 \mathrm{~km}$ and then increase strongly in the shear layer. This effect of shear generation on velocity variances was discussed by Turner

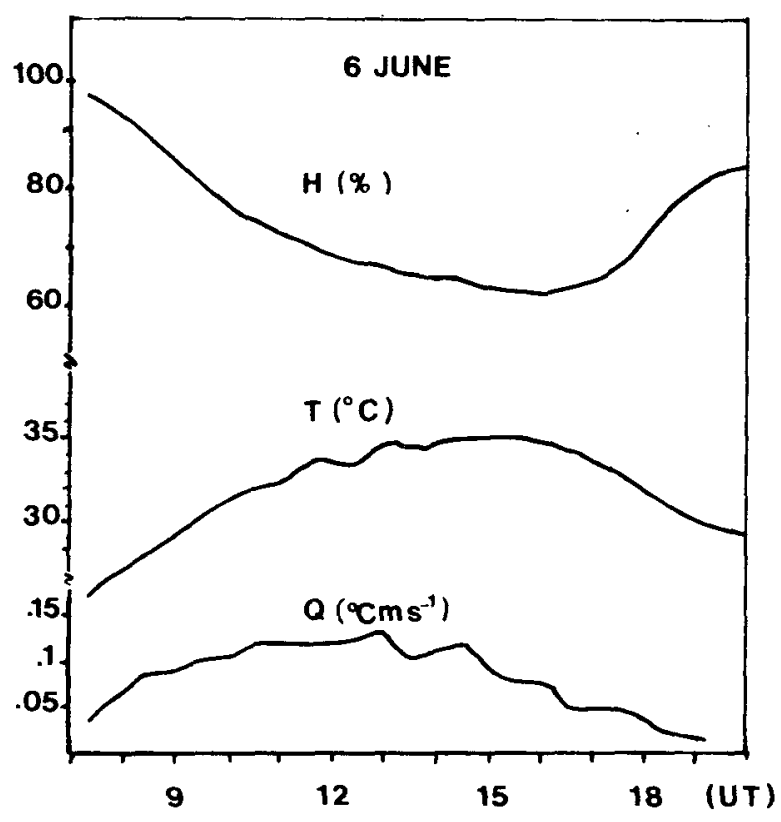

FIG. 4. Evolution during the day at Kothogo of the relative humidity $H$, the temperature $T$ and the virtual heat flux $Q$ near the surface. 

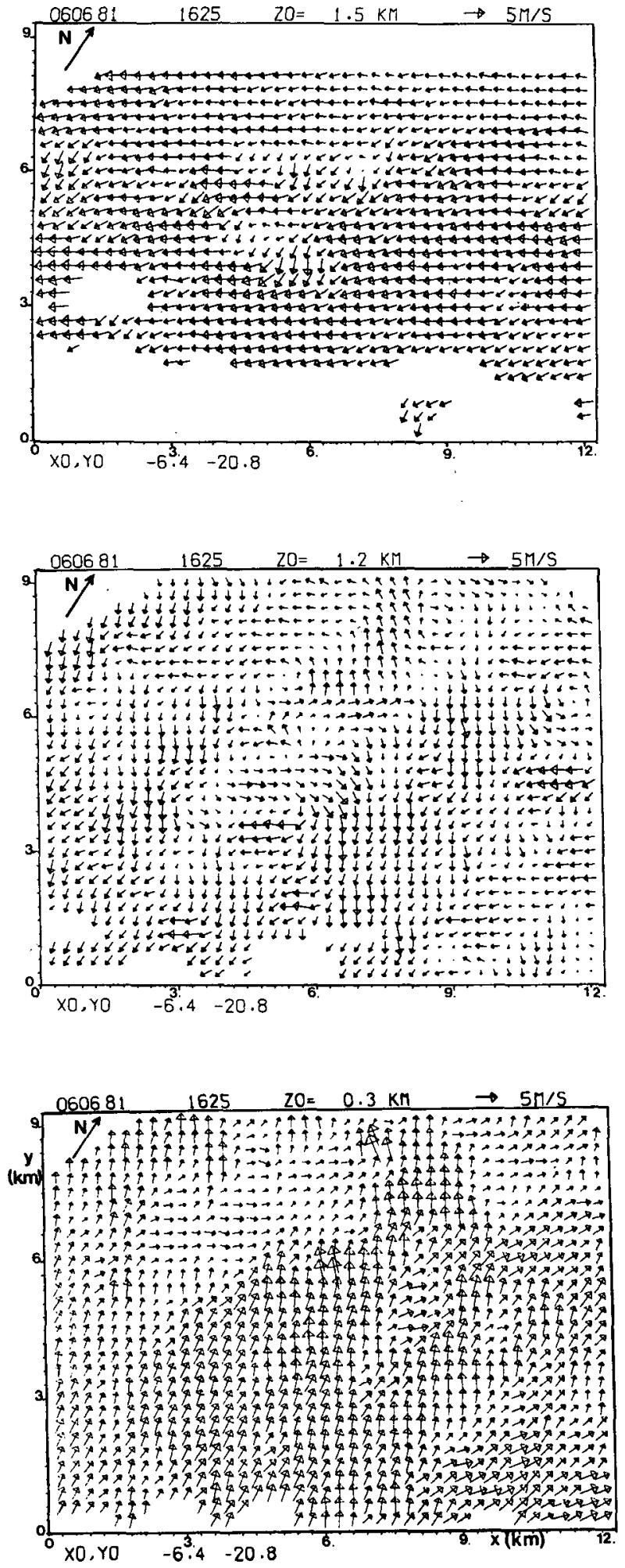

FiG. 5. Horizontal wind at 1625 for $z=0.3,1.2$ and $1.5 \mathrm{~km}$. The length of the $5 \mathrm{~m} \mathrm{~s}^{-1}$ wind vector is illustrated by an arrow above each figure. The origin is $\left(X_{0}, Y_{0}\right)$ with respect to the baseline center. The axes $X_{0} X$ and $Y_{0} Y$ are respectively parallel and perpendicular to the radar baseline (see Fig. 1). North is indicated by an arrow in the upper left corner of each figure.
(1973), also recently by Brost et al. (1982). Above a height of $1.4 \mathrm{~km}$, the horizontal variances decrease because of the easterly wind regularity.

Thus, the wind velocity variance profiles confirms that the convective layer structure is divided into three layers: free convection is observed below the shear $(0.9$ $\mathrm{km}$ ), then the shear strongly affects the mixed layer in a transition layer between 1 and $1.4 \mathrm{~km}$, and finally the inversion level is found in the regular easterly flow.

\section{2) Spatial organization of CONVEctive STRUCTURES}

A two-dimensional spectral analysis has been applied to the vertical velocity at every height level to determine the preponderant scales and corresponding orientations of the convective structures. The analysis process has been detailed in Eymard and Weill (1982). After selecting the significant peaks of each sequence, we have gathered them in the same spectral diagram (Fig. 7). In this figure, the wavenumber frame is referred to the geographic axis and only the centers of peaks are indicated, although they are sometimes broad. The location of a peak provides the wavelength and the direction of the convective structures at this scale, perpendicular to the wavenumber vector. At each sequence, two or three principal peaks are found; they take place in three broad areas circled on the figure. The corresponding scales are indicated in Table 1, as well as the mean scale characteristic of each area:

- The mean wavelength of area (1) is $2.4 \mathrm{~km}$, i.e., about $1.5 Z_{i}$, for a direction of alignment nearly parallel to north. This mode is established at 1541 and is observed mainly below the shear. The scale $1.5 Z_{i}$ is the convective scale, found in convective situations (Kaimal et al., 1976; Caughey and Palmer, 1979 and others).

- Gathered in area (2) are peaks of larger scale, between 3.5 and $6 \mathrm{~km}$, in mean $3.9 \mathrm{~km} \approx 2.5 Z_{i}$. The corresponding flow alignment is more imprecise than the previous, in mean at about $20-30^{\circ}$ clockwise of north. Peaks are generally observed in the whole convective layer, often with the greatest amplitude. This mode appears at 1551 and seems to disappear near 1620-1625 at which a peak of middle scale between modes $(1)$ and $(2)$ is found $\left(3.2 \mathrm{~km} \approx 2 Z_{i}\right)$.

- Finally, located in area (3) are peaks of mean scale $2 \mathrm{~km} \approx 1.2 Z_{i}$ corresponding to a flow orientation of $\sim 40^{\circ}$ clockwise of north. This scale is most common until 1541, after which it becomes weaker than the others, sometimes disappearing. It is principally found below the shear and above it, and is very weak inside this transition layer.

The remaining part of the spectral diagram (halfplane of positive $k_{y}$ only) contains very few peaks. The three areas delimit flow orientations between N-S and $45^{\circ}$ along a NE-SW direction. As homogeneous and 

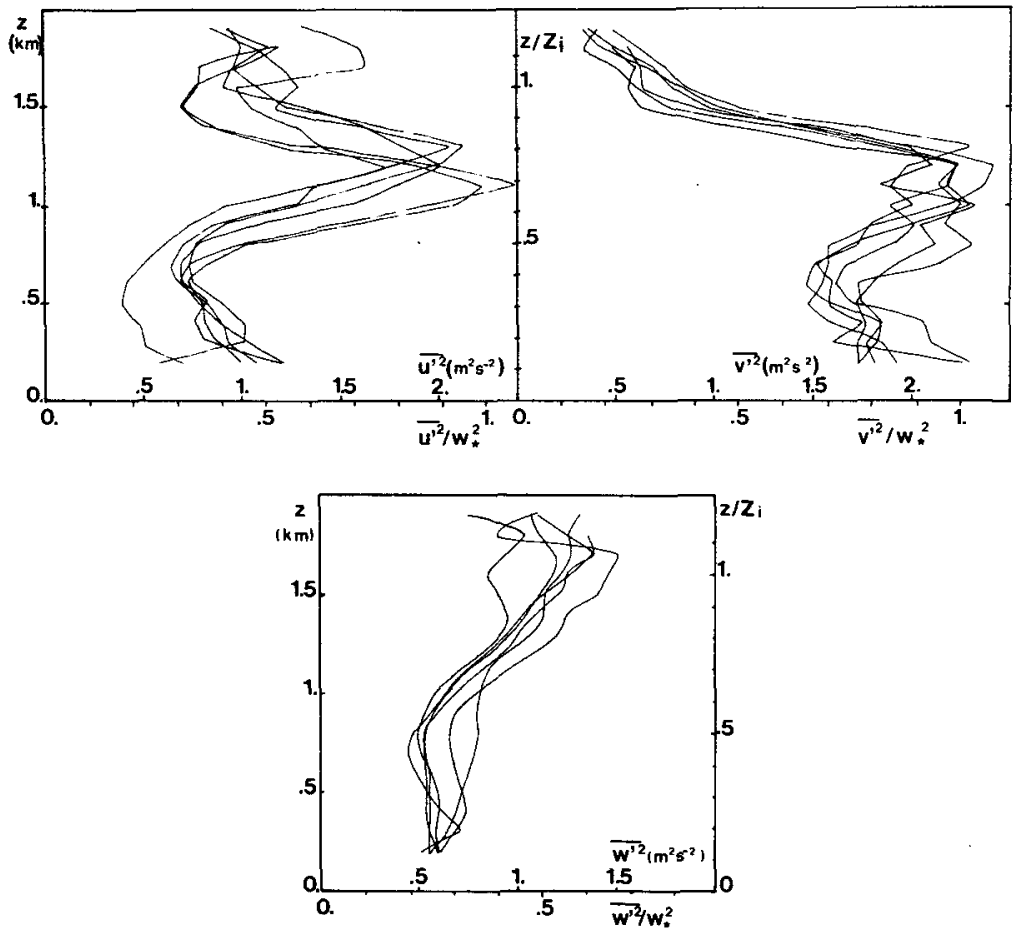

Fig. 6. Mean horizontal and vertical velocity variances from six sequences between 1540 and 1625 . At every level, the horizontal velocity components are taken with respect to the mean spatial wind direction. The convective velocity is measured at point $P$ in the radar domain. Its value is $w_{*}=1.5 \mathrm{~m} \mathrm{~s}^{-1}$.

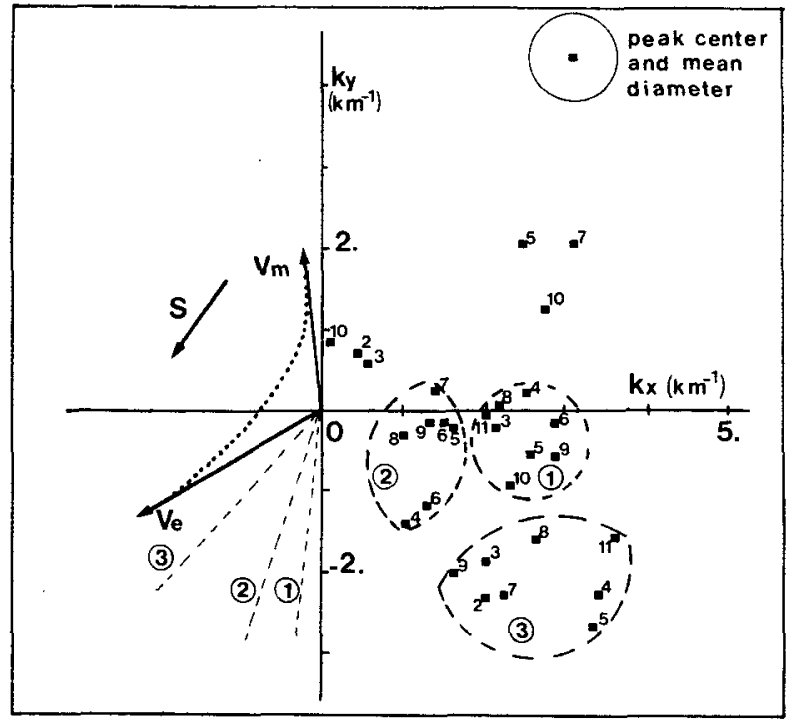

FIG. 7. Two-dimensional spectrum of the vertical velocity field. The wavenumber frame is referred to the geographic axis. Centers of the principal peaks from each sequence (noted by a number) are gathered. They define three areas noted (1), (2) and (3). The corresponding directions of alignment are indicated by dashed lines. The wind velocities as well as the wind hodograph between them are drawn in the monsoon layer $\left(V_{m}\right)$ at height $0.3 \mathrm{~km}$ and at the inversion level $\left(V_{e}\right)$. The arrow $(S)$ indicates the direction of the mean shear vector, perpendicular to the wind at $1.1 \mathrm{~km}$ (middle of the shear layer). random convective layer would have presented peaks in all directions, a convective organization is probable here, characterized by the mode of scale $2.5 Z_{i}$ superposed to convective scales. It is in agreement with observations of banded flows by Kuettner (1971), LeMone (1973), Berger and Doviak (1980) and others showing a typical spacing $2-4 Z_{i}$, between bands. To estimate the propagation velocity of the mode of scale $2.5 Z_{i}$, we determined the advection of the wind field using a two-dimensional cross-correlation between successive sequences. A Cressman weighting filter (1959) was used to filter out scales $<3 \mathrm{~km}$, neglecting large-scale effects. We obtain a propagation velocity $1.1 \pm 0.4 \mathrm{~m} \mathrm{~s}^{-1}$ toward the northwest constant with time during the whole experiment, corresponding to the wind speed at a height of $1.1-1.2 \mathrm{~km}$.

Causes of convective organization may be local or thermal instability (Harrold and Browning, 1971; Kropfli and Kohn, 1978), pure dynamic instability (Brown, 1970, 1972), or thermal instability modified by shear (Kuo, 1963; Asai, 1970, 1972). Finding, in our case, a stable propagation velocity over the duration of the experiment tends to eliminate local effects. It suggests an interpretation in terms of an unstable wave, as proposed in Asai's model (1972) in a thermally unstable boundary layer with a linear shear. The most unstable mode corresponds to bands parallel to the shear with a wavelength of $\sim 1.5 Z_{i}$ and a phase velocity 
TABLE I. Mean preponderant scales of each sequence, distributed among the three areas shown in Fig. 6. Angle brackets indicate the layer in which the peak is found: left angle bracket means below the shear and right angle bracket, above it.

\begin{tabular}{|c|c|c|c|c|c|c|c|c|c|c|c|}
\hline & \multicolumn{11}{|c|}{ Time (GMT) } \\
\hline & 1535 & 1541 & 1551 & 1556 & 1601 & 1607 & 1610 & 1615 & 1620 & 1625 & Mean \\
\hline (1) & & 2.3 & 2.6 & 2.4 & 2.2 & & 2.8 & 2.2 & 2.5 & 32 & 2.5 \\
\hline (2) & & & 3.4 & 3.7 & 3.7 & 4.6 & $5-6$ & $4.9^{\prime}$ & & & 3.9 \\
\hline (3) & 2. & 2.3 & \langle\rangle & $\stackrel{1.5}{\langle\rangle}$ & & 2. & 2.1 & 2.8 & & $\stackrel{1.6}{<}$ & 2. \\
\hline
\end{tabular}

similar to the smallest wind speed, transverse to the shear. Comparing this model with our results, we obtain a reasonable agreement (wavelength of $\sim 2.5 Z_{i}$, alignment close to the mean shear direction, and propagation as the smallest wind at $1.1 \mathrm{~km}$ ), taking into account the different basic states in both cases (the real shear is not linear).

We will now relate the cloud field properties to the convective subcloud layer organization.

\section{c. Dynamic structure of the cloud field}

Photogrammetry of the shallow cumulus clouds was performed from 1525 to 1650 with two cameras operating $1.5 \mathrm{~km}$ apart near $P$. Using triangulation, the sizes and locations of clouds may be determined through a circular area of radius about $12 \mathrm{~km}$ around $P$ (Bénech $e t$ al., 1983). The accuracy is a few hundred meters horizontally and about $100 \mathrm{~m}$ vertically. A fullsky camera took pictures above $\mathrm{P}$ (Fig. 8), providing the locations and horizontal sizes of clouds within 7 $\mathrm{km}$ from $\mathrm{P}$ (but without indication about heights). These pictures complement photogrammetry data available only for clouds farther than $2 \mathrm{~km}$ from $P$. The individual cloud evolution may be investigated, since pictures were taken every 2-5 min.

The geometric characteristics and evolution of 25 clouds have been examined by drawing cloud maps from photogrammetry pictures. An example of a cloud map (at 1607) in geographic coordinates is given in Fig. 9, also indicating the approximate cloud center locations with time. No clear evolution of the cloud layer appeared in the mean results for the whole experiment ( $90 \mathrm{~min}$ duration). They are summarized in Table 2, showing the following characteristics:

- Cloud base and top: cumuli are based near a height of $1.8 \mathrm{~km}$, a little above the lifting condensation level (from the temperature sounding at Korhogo), as also observed by Kitchen and Caughey (1981) and Warner (1973). This height, though, is higher than the inversion level $(1.6 \mathrm{~km})$ and clouds are found in a drier atmosphere. A possible explanation following Manton (1978) and Augstein (1978) is that convective patches penetrate upward through the stable layer where they reach the condensation level. However, another ex- planation may be that the inversion rises above the clouds as observed by Kitchen and Caughey (1981): the amplitude variation of the inversion height is of the order of the cloud depth. Regardless, the chaff often reaches heights of $1.9-2 \mathrm{~km}$ in cloudy areas but is generally limited to $1.5-1.6 \mathrm{~km}$ in clear air supporting both explanations. On the other hand, cumuli present a weak vertical growth, perhaps because they develop in a layer with lower humidity and because the convective activity has decreased since 1300 [from the surface heat flux (Fig. 2)].

- Diameter, shape and distribution (see Fig. 9): small clouds are roughly circular, of diameter $1-2 \mathrm{~km}$. Larger clouds are often elongated, being 4-5 km long but 1$2 \mathrm{~km}$ wide (three cases). On the other hand, the cloud distribution is not homogeneous, as most of them are found a few kilometers NNW from P, often joined at their base. Elsewhere, only isolated cumuli appear and

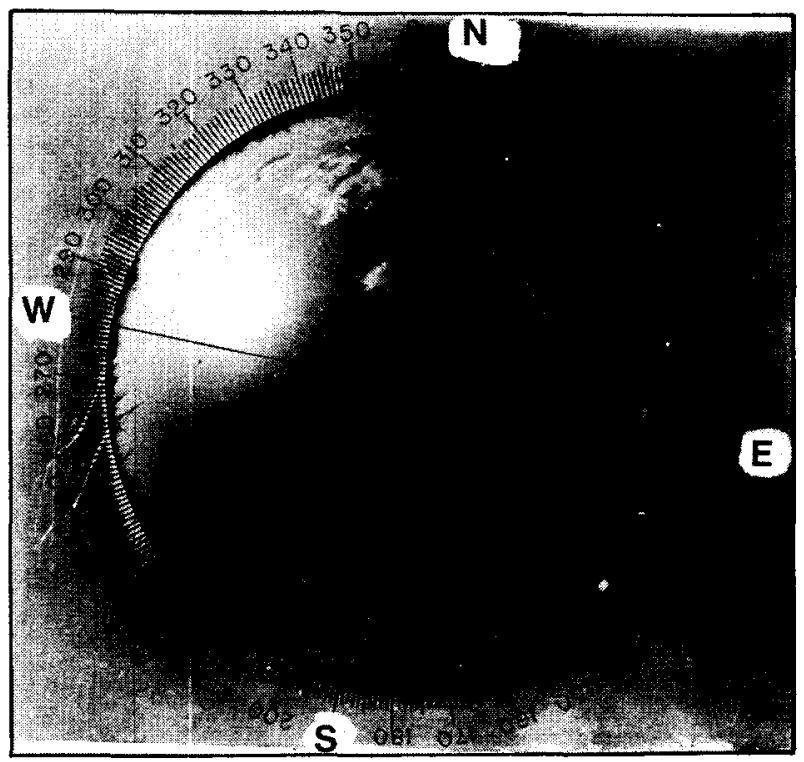

FIG. 8. Example of full-sky camera picture taken at 1607 . Clouds are principally observed north and east of $P$ (center of the figure). Some of them, north of $\mathrm{P}$, are elongated along the direction NE-SW. 


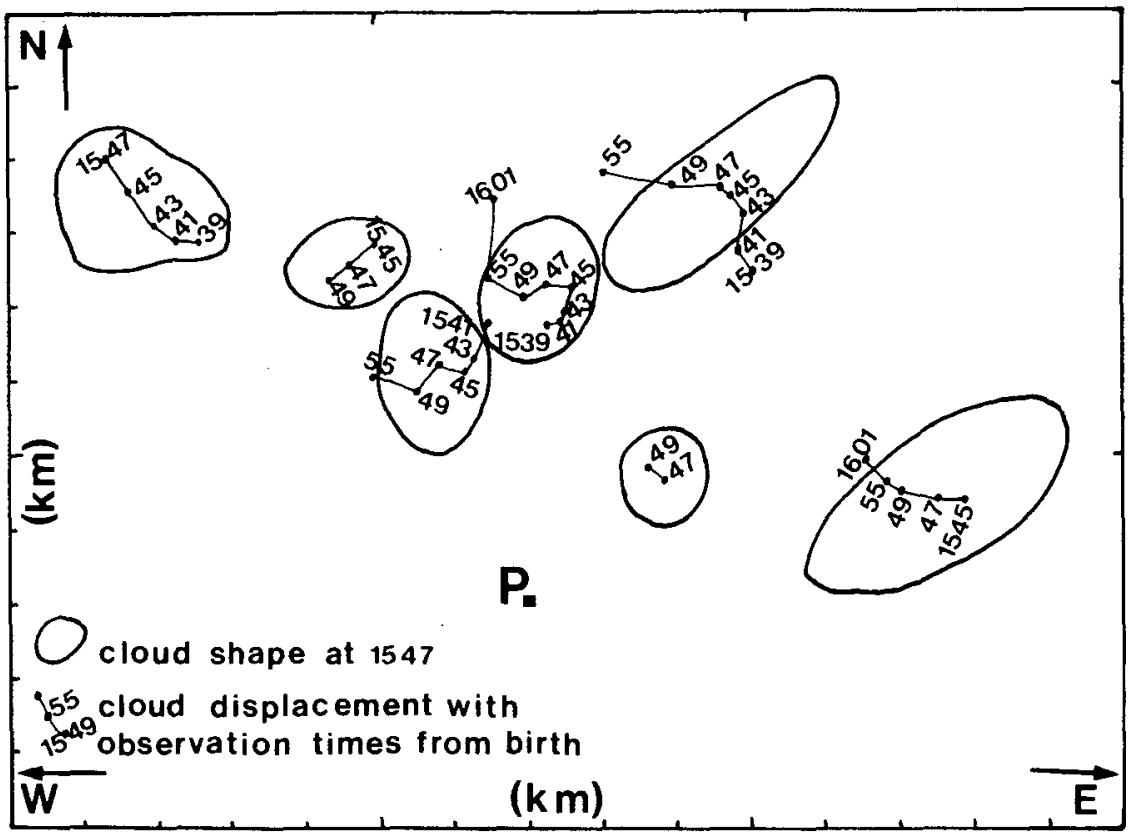

FIG. 9. Schematic cloud map at 1547 in geographic axis: the main clouds are drawn, as well as their trajectories, from birth to death. Observational times are noted by the minutes after 1500 or 1600 .

almost no cloud is found south of $P$. This indicates a spatial convective heterogeneity, which could be due to thermal heterogeneity, as shown in Fig. 1 on which half-hour mean temperatures (between 1530 and 1600) have been indicated at several surface stations. No temperature higher than $33.5^{\circ} \mathrm{C}$ is observed southeast of P. Moreover, the area between $\mathrm{P}$ and the stations north and northwest of $P$ where most of the observed clouds are formed is particularly warm. As the most cloudy area is located inside the radar domain, it is possible to compare the cloud patterns with the spectral characteristics of the subcloud layer: the small cloud's

TABLE 2. Mean cloud properties.

\begin{tabular}{lll}
\hline \hline & Mean and limits & Comments \\
\hline Base height & $1.8 \pm 0.15(\mathrm{~km})$ & $\begin{array}{c}\text { Weak variability with } \\
\text { time }\end{array}$ \\
Top height & $2.2(2$. to $2.7 \mathrm{~km})$ & Few reach $2.5-2.7 \mathrm{~km}$ \\
Diameter & 1 to $4 \mathrm{~km}$ \\
Shape & $\begin{array}{l}\text { circular (about } 15 \text { small clouds) to elongated } \\
\text { along the NE-SW direction (3 cases) }\end{array}$ \\
Distribution & $\begin{array}{l}\text { heterogeneous: few clouds at south of P; most } \\
\text { are close to each other or joined at their } \\
\text { base (at } 8 \mathrm{~km} \text { north of P) }\end{array}$ \\
Displacement & $\begin{array}{l}\text { from stationary to speed } 3 \mathrm{~m} \mathrm{~s} \mathrm{~s}^{-1} \\
\left.\text { (average } 2 \mathrm{~m} \mathrm{~s} \mathrm{~s}^{-1}\right)\end{array}$ \\
Lifetime & $\begin{array}{l}\text { average 20 min [from } 5 \text { min (1 case) to more } \\
\text { than } 50 \text { min] }\end{array}$ \\
\hline
\end{tabular}

diameter is in the range of the convective scale (2-2.5 $\mathrm{km}$ ). On the other hand, some larger cumuli (including joined clouds) are elongated along a NE-SW direction, which is the mean orientation of the convective structures. For example, a convergence line is shown in Fig. 3 at a height of $0.3 \mathrm{~km}$, corresponding to strong convective structures. These cells are capped by joined clouds aligned along the convergence direction. Fig. 10 shows the vertical velocity at contour intervals of $0.7 \mathrm{~m} \mathrm{~s}^{-1}$ from 0.2 to $1.8 \mathrm{~km}$ (the lack of chaff explains the few contour lines at this height).

- Cloud displacement and evolution: Fig. 9 shows the cloud center locations during their life cycle from successive pictures. Their displacements appear inhomogenous-often nearly stationary during several minutes, they move toward the northwest with an average speed of $\sim 2 \mathrm{~m} \mathrm{~s}^{-1}$, with a rather great dispersion between north and west. Since the easterly wind blows toward the WSW ( $120^{\circ}$ from north) at cloud level, these small cumuli are not wind tracers. Their displacement may be related to the convective organization since cumuli are initiated by convective structures in the mixed layer. They present a tendency to be aligned along the NE-SW and travel toward the northwest, transverse to the mean shear direction, similar to the largest mode $\left(2.5 Z_{i}\right)$ found in the subcloud layer.

The observation of clouds above the radar domain will allow us to study the convective layer from another point of view. After looking at spatially averaged dy- 


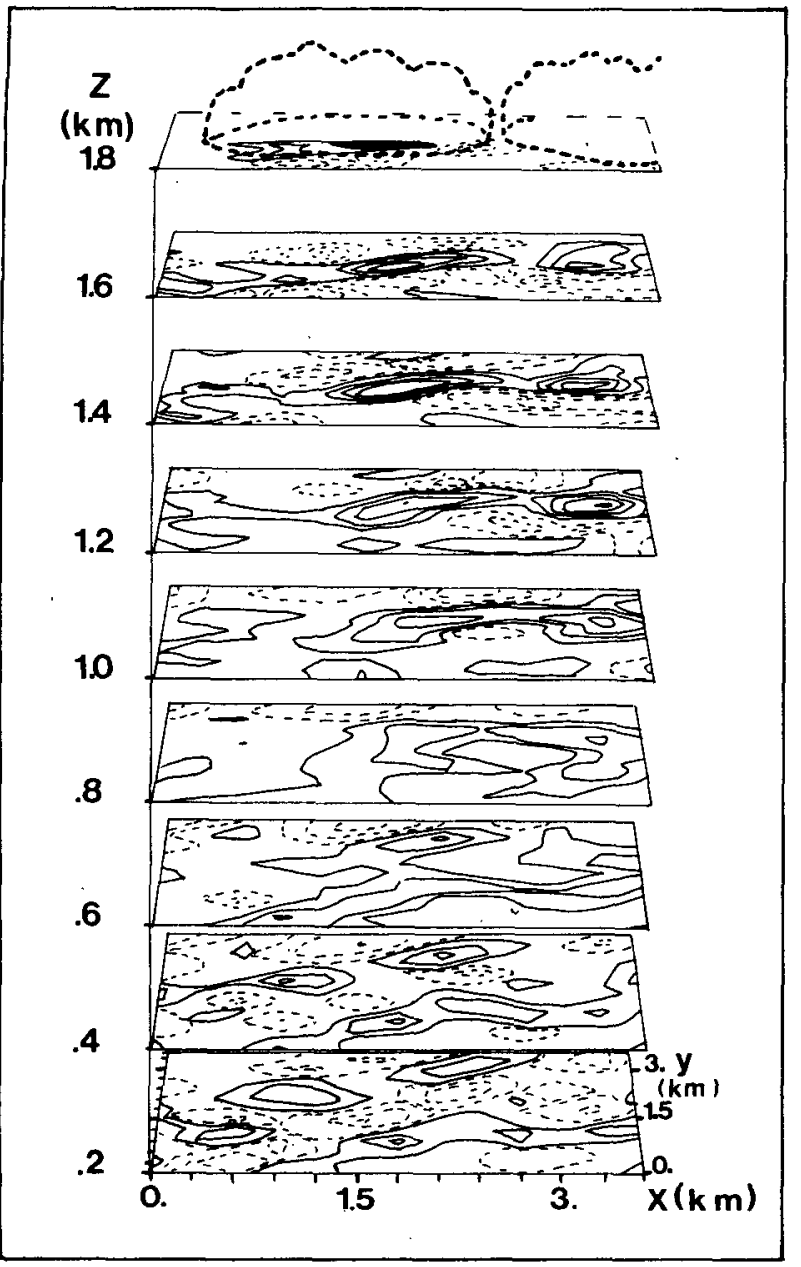

FIG. 10. Perspective view of vertical velocity contours with a step of $0.7 \mathrm{~m} \mathrm{~s}^{-1}$ in horizontal planes from heights of 0.2 to $1.8 \mathrm{~km}$. Solid lines correspond to updrafts, dashed lines to downdrafts. The locations of two clouds observed at that time (1625) are indicated on the highest plane.

namic properties, we shall now distinguish areas capped by clouds from clear-air areas. From two-dimensional spectral analysis, the scale of organized convection $(3.6-3.9 \mathrm{~km})$ is the preponderant scale and is also larger than the mean cloud size. As most of the energy in this convective situation is taken into account, we shall examine the dynamics and vertical energy transports of subcloud and clear-air areas at this scale.

\section{Dynamic structures of cloudy and clear-air topped volumes in the convective layer}

\section{a. Defining the studied volumes}

Among the 25 clouds observed by photogrammetry, eight have been chosen to be placed above the radar wind field (clouds of very short lifetime, small size or on the edges of the radar domain have been eliminated). However, their evolution is slow enough for placing them on several successive wind fields. As noted in the previous section, the evolution of the cloud layer is negligible during the experiment. Neglecting the fact that the same cloud is considered several times, we obtain 18 cloud-topped areas. The locations of all cloud centers are indicated in Table 3.

In order to compare their properties with those of clear-air regions, volumes with square bases of the same area are defined in both cases. The square size is 3.6 to $3.9 \mathrm{~km}$, providing at every level $140-160$ grid points, a sufficient number for calculating statistical averages.

The clear-air volumes are defined at each sequence, as far as possible from the cloudy areas, to be sure of their independence of effects of clouds. Some of them correspond to the same area observed at successive sequences. In this way, 12 clear-air volumes are considered. In the following, cloud-capped volumes will be noted $\mathrm{CCV}$ and the clear-air volumes CAV.

First we shall examine horizontal divergence and vorticity, and horizontal and vertical velocity variances, then momentum fluxes and shear stress production will be compared.

Before beginning this quantitative comparison, it must be noted that there are important differences in chaff diffusion between cloudy and clear-air volumes. At $1.7 \mathrm{~km}, 8 \mathrm{CCV}$ 's still contain a total of more than 100 points, in contrast to only 2 CAV's. The presence of clouds and associated entrainment improves the chaff diffusion, whereas the inversion layer at height $1.6 \mathrm{~km}$ stops the vertical diffusion in clear air. Because of this difference, CAV profiles will be limited to a height of $1.5 \mathrm{~km}$.

TABLE 3. Locations of cloud centers with respect to the radar baseline center.

The sequences used are those with the best resolution $0.3 \mathrm{~km} \times 0.3 \mathrm{~km} \times 0.1 \mathrm{~km}$.

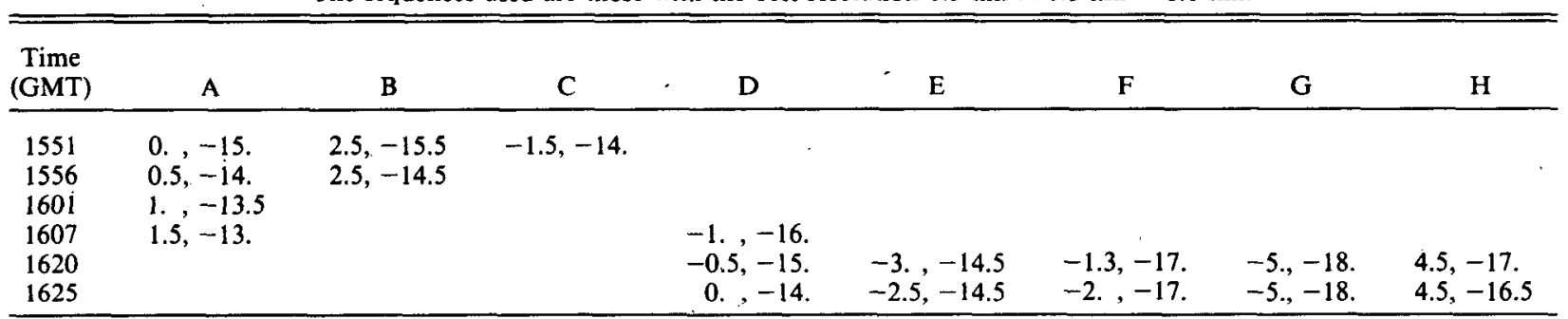




\section{b. Horizontal-divergence and vorticity}

From the horizontal velocity components at grid points, the divergence and vorticity are calculated using spline differentiation. Taking their average at every level provides the divergence and vorticity at the 3.5$4 \mathrm{~km}$ scale. In this case and below, confidence intervals for each average are determined using the Student's $t$-test for a $95 \%$ confidence assuming Gaussian distributions. Fig. 11 presents divergence and vorticity profiles for CCV and CAV. The divergence profiles show differences between CCV and CAV at low levels and in the shear layer. The cloudy volumes are convergent (about $-0.2 \times 10^{-3} \mathrm{~s}^{-1}$ ) up to $0.6 \mathrm{~km}$ and then become divergent (reaching $0.5 \times 10^{-3} \mathrm{~s}^{-1}$ at height of $1.3 \mathrm{~km}$ ), whereas the CAV are neither convergent nor divergent.

Hence, clouds are associated with strong updrafts at low levels, as shown in the example in Fig. 10. At shear level, close to cloud base, the mean CCV vertical velocity is found to be generally negative. This means that updrafts cover only a small fraction of the total area, as proposed in models by Asai and Kasahara (1966), Augstein et al. (1973), or observed by Greenhut and Khalsa (1982) and others. The measured divergence is therefore probably due to entrained air around updrafts.

On the contrary, the vertical component of vorticity profiles principally shows the dispersion between individual measurements either in CCV or CAV: weak averages, but broad confidence intervals are observed. Magono and Hozumi (1982) found rotations to occur in the direction of the vertical shear in the cloud layer, but Frisch et al. (1976) and Kitchen and Caughey (1981) observed both cyclonic and anticyclonic rotations. The increase of the CAV vorticity above $1.2 \mathrm{~km}$ is probably not significant because of the very broad confidence intervals. Thus, cloud-capped volumes are characterized by their divergence profiles, whereas vorticity only indicates a great variability at this scale.

\section{c. Velocity variances}

The horizontal velocity components are referred to as the layer mean monsoon wind direction between 0.2 and $0.8 \mathrm{~km}, u$ being the parallel component and $v$ the transverse one. The $u$ - and $v$-variance profiles are shown in Fig. 12, in which the convective velocity $w_{*}$ (at $\left.(P)\right]$ is used to normalize variances. The $u$-variances are small below $0.8 \mathrm{~km}\left(\approx 0.25 w_{*}^{2}\right)$ but the $\mathrm{CCV} \overline{u^{\prime 2}}$ is greater by $0.2 \mathrm{~m}^{2} \mathrm{~s}^{-2}$ than the CAV. Above, they increase, reaching together about $0.6 w_{*}^{2}$ at 1.2 $\mathrm{km}$. This is due to the shear production and they rapidly decrease above $1.2 \mathrm{~km}$. Both $v$-variances present the same profile with a broad confidence interval below $1.7 \mathrm{~km}$. They are greater than the $u$-variances, being of the order of $0.4-0.6 w_{*}^{2}$. This difference is due to the convective organization, since the flow orientation is closer to the monsoon wind direction than to the transverse one. Above $1.2 \mathrm{~km}$, variances rapidly decrease with height, separating from each other.

On $u$ - and $v$-variance profiles, CCV values are generally a little greater than CAV values, but no simple explanation may be put forward. However, the convective organization is not spatially homogeneous: it

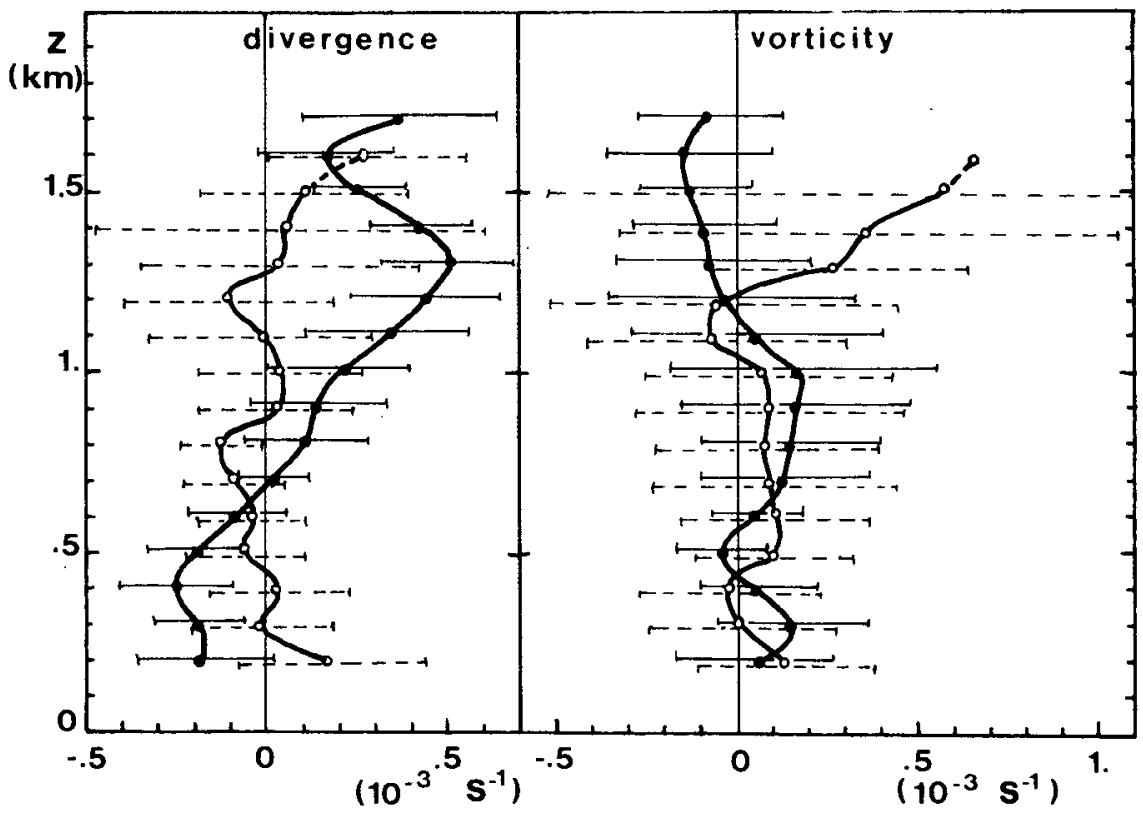

FiG. 11. Mean horizontal divergence and vorticity profiles for cloudy capped volumes (dots) and clear air volumes (circles). Averages are taken in horizontal areas of surface $4 \times 4 \mathrm{~km}^{2}$. The solid and dashed intervals indicate the respective confidence intervals for $95 \%$ confidence. 


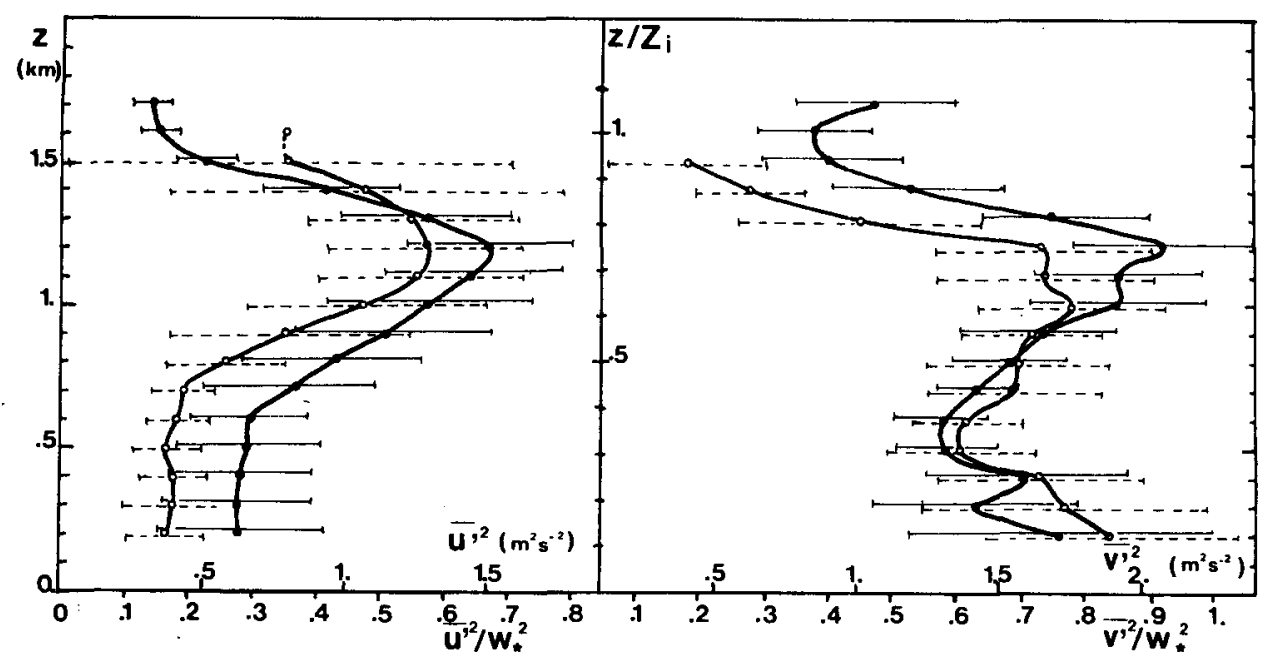

FIG. 12. As in Fig. 11 but for horizontal velocity variances for CCV and CAV; $u$ and $v$ are calculated with respect to the monsoon wind.

perhaps affects cloudy areas more than the fairly distant clear-air regions (see Fig. 9). Therefore, strong velocity perturbations in the vicinity of convergence or divergence zones beneath clouds could increase the variances.

Vertical velocity variances $\overline{w^{2}}$ (Fig. 13) present a slight maximum at a height of $0.4 \mathrm{~km}(0.27$ and $0.32 w_{*}^{2}$ ) and decrease up to $0.8 \mathrm{~km}$. The stronger $\mathrm{CCV}$ buoyancy is the cause of the difference between profiles, as is shown by the upward velocity variances $\left(w_{u}^{\prime 2}\right)$ at the same height (Fig. 13). A similar difference is found between $\mathrm{CCV}$ variances and the mean largescale variance studied in Section 3b: as there is no energy peak at scales $\geqslant 4 \mathrm{~km}$, this difference shows that the presence of several clouds of relatively small area does not influence the mean behavior of the mixed layer. Above $0.8 \mathrm{~km}$, both variances increase up to $1.2 \mathrm{~km}$ because of shear production. Above $1.2 \mathrm{~km}$, the $\mathrm{CAV}$ variance is almost constant, whereas the $\mathrm{CCV}$ variance still increases with height. This is essentially due to entrainment around cloud edges as the downward velocity variance $\left(\overline{w_{d}^{\prime 2}}\right)$ shows (Fig. 13). But there may also be contribution of latent heat release at cloud base and possibly radiative cooling, following Brost $e t$ al. (1982).

The entrainment effect may be estimated by comparing variances, following Deardorf (1979). When looking at variances at the inversion level (cloud top) he found a rate $\overline{w^{\prime 2} c a} / w^{\prime 2} c \approx 0.3\left[w^{\prime 2} c a\right.$ the clear air variance and $\overline{w^{\prime 2}} c$ the cloudy-air variance] in the case of stratocumulus clouds. As we have no information about the cloud top, we may only compare variances at cloud base with clear-air variances. Using Deardorff's profiles, a ratio of 0.35-0.4 is found between clear-air variances at the inversion level and cloud base variances. When calculating the ratio between CAV vari-

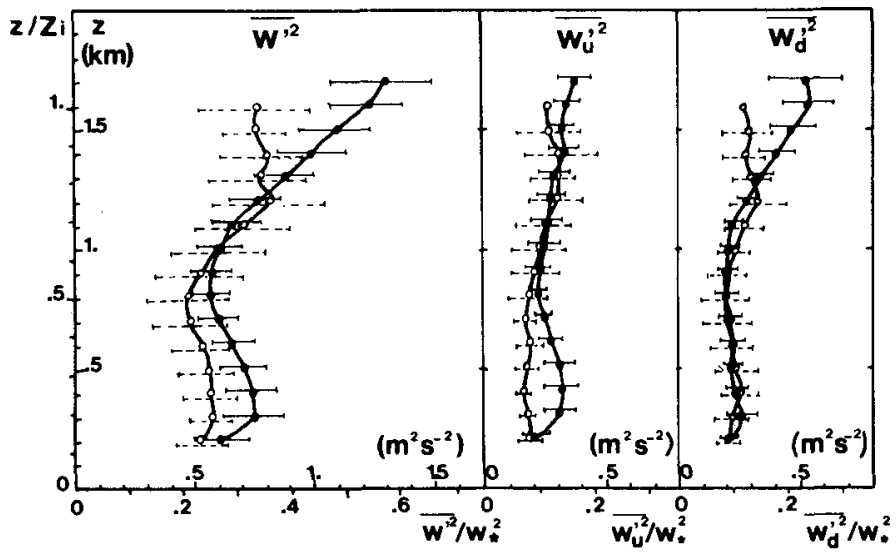

FIG. 13. As in Fig. 12 but for vertical velocity $(w)$, upward velocity $\left(w_{u}\right)$ and downward velocity $\left(w_{d}\right)$ variances. 
ance at $1.5 \mathrm{~km}$ and CCV variance at $1.7 \mathrm{~km}$, we obtain the value 0.57 . This value, greater than his, is partly due to the different kinds of clouds, shallow cumuli instead of stratocumuli, which are generally associated with a stronger inversion. However, we do not take into account the small-scale variance which could modify the result.

$\mathrm{CCV}$ vertical variance is therefore greater than the CAV at low levels because of greater buoyancy, and near the top of the mixed layer because of entrainment around clouds. This last difference is great enough to suggest that the clouds actually penetrate the inversion, so that the loss of mass is compensated by entrained air. On the other hand, in the shear layer, the CAV and $\mathrm{CCV}$ velocity variances are increasing in the same manner. We will now examine the shear production, the cause of this increase.

\section{d. Momentum fluxes and production}

Momentum fluxes $\overline{u^{\prime} w^{\prime}}$ and $\overline{v^{\prime} w^{\prime}}$ are computed through a two-dimensional cross-correlation on the horizontal CCV and CAV areas [as for variances, they do not include scales smaller than 3 grid lengths $(0.9$ $\mathrm{km})$ ]. The shear stress production is

$$
M=-\left(\overline{u^{\prime} w^{\prime}} \frac{d U}{d z}+\overline{v^{\prime} w^{\prime}} \frac{d V}{d z}\right)
$$

where $U$ and $V$ are the mean horizontal wind components within the areas (velocities are still referred to the monsoon wind direction). The shear vector is determined using a second-order polynomial differentiation. Here, $M$ is calculated between heights of 0.3 and $1.6 \mathrm{~km}$ for $\mathrm{CCV}$ and between 0.3 and $1.4 \mathrm{~km}$ for CAV.

Fig. 14 shows the mean fluxes and production [the friction velocity, $u_{*} \approx 0.27 \mathrm{~m} \mathrm{~s}^{-1}$, is measured at the meteorological station at Korhogo (R1)]. Below the shear level, both $\overline{u^{\prime} w^{\prime}}$ and $\overline{v^{\prime} w^{\prime}}$ are weak, about 0.01 $\mathrm{m}^{2} \mathrm{~s}^{-2}$. Despite the small-scale filtering, they are in the range of values found by Jensen and Lenshow (1978) or Nicholls and LeMone (1980), but smaller than those found by Lenshow et al. (1980), Kaimal et al. (1976) or Rabin et al. (1982) at larger scale in the case of rolls. This weakness is due to the light wind in this layer. Above $1 \mathrm{~km}$, fluxes increase because of the shear, reaching $0.02 \mathrm{~m}^{2} \mathrm{~s}^{-2}\left(\sim 0.3 u_{*}^{2}\right)$ in absolute values. At any level, few differences appear between $\mathrm{CCV}$ and $\mathrm{CAV}$, taking into account the uncertainties.

This is also observed on shear production profiles. Both CCV and CAV profiles present similar shapes. In the mixed layer below the shear level, $M$ is close to zero, since the wind is regular, then increases with height, reaching $0.2 \times 10^{-3} \mathrm{~m}^{2} \mathrm{~s}^{-3}$ at $1.5 \mathrm{~km}$.

Thus, the shear production is rather small although the shear is the probable cause of the convective organization. This means perhaps that the preponderant scale for momentum production is larger than the convective scale, as in the case of rolls described by Rabin et al. (1982).

However, this comparison between clear-air and cloudy capped volumes shows that the greater convective activity below clouds is discernible at the scales resolved by radars. On the other hand, the shear is found to equally affect $\mathrm{CCV}$ and $\mathrm{CAV}$, increasing variances and momentum fluxes, but the momentum production is rather small at the convective scale.

\section{Conclusion}

Spatial properties of a tropical cloudy boundary layer have been studied using radar velocity data and photogrammetry. Despite the small-scale filtering, the radar analysis provided us information about the spatial structure of the subcloud boundary layer and allowed us to study second-order moments. Both subcloud and cloud layer means and a statistical comparison of areas beneath clouds and in clear air have been presented with the following results:

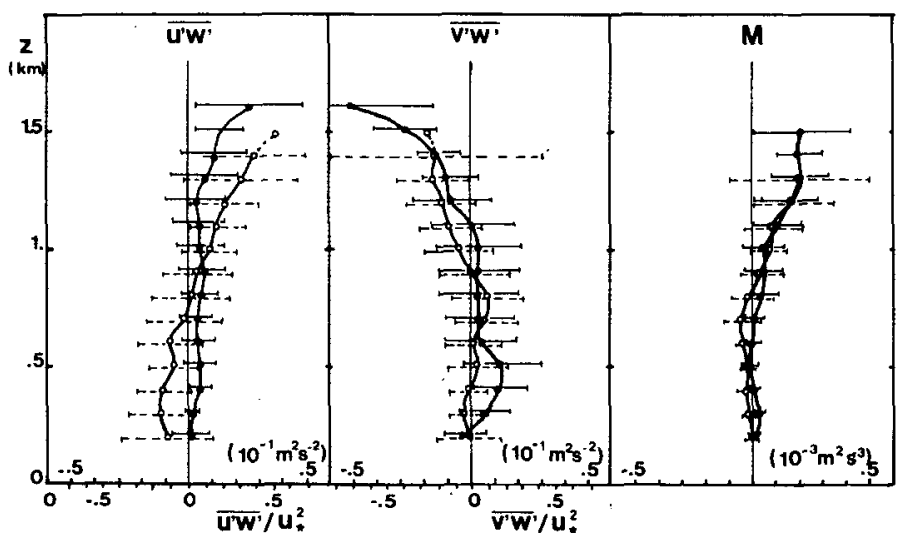

FIG. 14. Momentum fluxes and shear stress production $M$. Notation is similar to that of previous figures; $u_{*}$ is measured at Korhogo and is of the order of $0.27 \mathrm{~m} \mathrm{~s}^{-1}$ 
1) The mean characteristics of the mixed layer are strongly influenced by the shear between the monsoon and the easterly winds; important variances are found at its level with respect to the monsoon layer values. The shear appears to be the cause of the observed convective organization of scale $2.5 Z_{i}$, which is oriented along a NE-SW, a direction close to the shear vector, and propagates at the smallest wind speed, transverse to the shear, as suggested by Asai (1972).

2) The cloud layer presents some characteristics similar to the subcloud convective layer-the same range of scales (2-4 km) and a tendency also to be aligned along the NE-SW direction. However, two aspects are unusual: clouds are formed in the easterly flow, above the measured inversion level in clear air suggesting that clouds penetrate the inversion. On the other hand, clouds travel toward the northwest, different from the easterly wind or the monsoon wind direction, but in agreement with the convective organization.

3) By locating cumuli above the radar wind field, respective properties of subcloud and clear air areas have been determined, providing the following results:

- The horizontal divergence is modified by clouds, presenting a convergence at low levels and a divergence above. The individual vorticity shows a great variability without any characteristic mean behavior.

- Horizontal and vertical velocity variances are greater below clouds. In particular, the difference of $0.2 \mathrm{~m}^{2} \mathrm{~s}^{-2}$ between vertical variances in the mixed layer indicates a greater buoyancy below clouds.

- Entrainment also increases vertical variances near the top of the convective layer below clouds, confirming that the inversion is crossed by strong updrafts.

- Momentum fluxes and production look similar in both cases and differ from zero only in the shear layer. The shear, therefore, has no direct influence on the cloud formation at the convective scale, but it is an important factor in the boundary layer dynamics: it is probably the cause of the convective organization and it is involved in the energy exchanges through velocity variances and momentum production.

This study concerned the mesoscale spatial structure of a tropical boundary layer and showed the ability of radar to study the problem of deep convection initiation. However, to achieve a better understanding of the relation between the cloud layer properties and the subcloud layer, a more complete experiment would be necessary, including dynamic and thermodynamic measurements inside clouds.

Acknowledgments. I am indebted to A. Weill for his helpful advices during this work. I wish to thank all persons from C.R.P.E., E.E.R.M., I.O.P.G. and L.A.M.P. who participated in the experiment and made possible the data acquisition and analysis. I also acknowledge $\mathrm{C}$. Gal for typing the manuscript. This work was supported by C.N.E.T. and I.N.A.G.

\section{REFERENCES}

Asai, T., 1970: Stability of a plane parallel flow with variable vertical shear and unstable stratification. J. Meteor. Soc. Japan, 48, 129-139.

- 1972: Thermal instability of a shear flow turning the direction with height. J. Meteor. Soc. Japan, 50, 525-532.

- and A. Kasahara, 1966: A theoretical study of the compensating downward motions associated with cumulus clouds. J. Atmos. Sci., 24, 487-496.

Augstein, E. H., 1978: The cloud layer. Short course on the planetary boundary layer, Boulder, Amer. Meteor. Soc., 1-50.

- H. Riehl, F. Ostapoff and V. Wagner, 1973: Mass and energy transports in an undisturbed Atlantic trade-wind flow. Mon. Wea. Rev., 101, 101-111.

Bénech, B., J. C. Mesnager and Pham Van Dinh, 1983: Système radiocommandé de photogrammétrie appliqué à la Physique de l'Atmosphère. Note 66 IOPG, Université de Clermont II, $67 \mathrm{pp}$.

Berger, M. I., and R. J. Doviak, 1980: Dual Doppler radar observations of wind fields in a dry convective boundary layer. Preprints 19th Conf. Radar Meteorology, Miami, Amer. Meteor. Soc., 219-226.

Betts, A. K., 1975: Parametric interpretation of trade-wind cumulus budget studies. J. Atmos. Sci., 32, 1934-1945.

_ 1976: Modeling subcloud layer structure and interaction with a shallow cumulus layer. J. Atmos. Sci., 33, 2363-2382.

Brost, R. A., J. C. Wyngaard and D. H. Lenshow, 1982: Marine stratocumulus layers. Part II: Turbulence budgets. J. Atmos. Sci., 39, 819-836.

Brown, R. A., 1970: A secondary flow model on the planetary boundary layer. J. Atmos. Sci., 27, 742-757.

- 1972: On the inflection point instability of a stratified Ekman boundary layer. J. Atmos. Sci., 29, 850-859.

Caughey, S. J., and C. J. Readings, 1974: Vertical component of turbulence in convective conditions. Advances in Geophysics, Vol. 18A, Academic Press, 125-130.

- and S. G. Palmer, 1979: Some aspects of turbulence structure through the depth of the convective boundary layer. Quart. $J$. Roy. Meteor. Soc., 105, 811-827.

Chong, M., and J. Testud, 1983: Three-dimensional wind field analysis from dual-Doppler radar data. Part 3: The boundary condition: An optimum determination based on a variational concept. $J$. Climate Appl. Meteor., 22, 1227-1241.

,-- and F. Roux, 1983: Three-dimensional wind field analysis from dual-Doppler radar data. Part 2: Minimizing the error due to temporal variation. J. Climate Appl. Meteor., 22, 12161226.

Cressman, G. W., 1959: An operational objective analysis system. Mon. Wea. Rev., 87, 367-374.

Deardorff, J. W., 1973: An explanation of anomalously large Reynolds Stresses within the convective planetary boundary layer. $\mathrm{J}$. Atmos. Sci., 30, 1070-1076.

- 1979: Stratocumulus-capped mixed layers derived from a threedimensional model. Bound.-Layer Meteor., 18, 495-527.

Emanuel, K. A., 1981: A similarity theory for unsaturated downdrafts within clouds. J. Atmos. Sci., 38, 1541-1557.

Eymard, L., and A. Weill, 1982: Investigation of clear air convective structures in the PBL using a dual Doppler radar and a Doppler sodar. J. Appl. Meteor., 21, 1891-1906.

Frisch, A. S., R. B. Chadwick, W. R. Moninger and J. M. Young, 1976: Observation of boundary layer convection cells measured by dual Doppler radar and echosonde and by microbarograph array. Bound.-Layer Meteor., 10, 55-68.

Greenhut, G. K., and S. J. S. Khalsa, 1982: Updraft and downdraft 
events in the atmospheric boundary layer over the equatorial Pacific Ocean. J. Atmos. Sci., 39, 141-156.

Harrold, T. W., and K. A. Browning, 197I: Identification of preferred areas of shower development by means of high power radar. Quart. J. Roy. Meteor. Soc., 97, 330-339.

Jensen, N. O., and D. M. Lenshow, 1978: An observational investigation of penetrative convection. J. Atmos. Sci., 35, 19241933.

Kaimal, J. C., J. C. Wyngaard, D. A. Haugen, O. R. Cote, Y. Izumi, S. J. Caughey and C. J. Readings, 1976: Turbulence structure in the convective boundary layer. J. Atmos. Sci., 33, 21522169.

Kitchen, M., and S. J. Caughey, 1981: Tethered balloon observations of the structure of small cumulus clouds. Quart. J. Roy. Meteor. Soc., 107, 853-874.

Kropfli, R. A., and N. M. Kohn, 1978: Persistent horizontal rolls in the urban mixed layer as revealed by dual-Doppler radar. $J$. Appl. Meteor., 17, 669-676.

Kuettner, J., 1971: Cloud bands in the earth's atmosphere: Observations and theory. Tellus, 23, 404-425.

Kuo, H. L., 1963: Perturbations of plane Couette flow in stratified fluid and origin of cloud streets. Phys. Fluids 6, 195-212.

LeMone, M. A., 1973: The structure and dynamics of horizontal roll vortices in the PBL. J. Atmos. Sci., 30, 1077-1091.

Lenshow, D. H., J. C. Wyngaard and W. T. Pennell, 1980: Meanfield and second-moment budgets in a baroclinic, convective boundary layer. J. Atmos. Sci., 37, 1313-1326.

Magono, C., and K. Hozumi, 1982: The rotational motion of cumulus clouds under vertical wind shear. J. Meteor. Soc. Japan, 60, 700-708.

Manton, M. J., 1978: Moist penetrative convection and the formation of incipient cloud. Bound.-Layer Meteor., 15, 265-287.

- 1981: A model of fair-weather cumulus convection. Bound.Layer Meteor., 22, 91-107.

Miller, L. J., and R. G. Strauch, 1974: A dual Doppler radar method for the determination of wind velocities within precipitating weather systems. Remote Sens. Environ., 3, 219-235.

Nicholls, S., and M. A. LeMone, 1980: The fair weather boundary layer in GATE: The relationship of subcloud fluxes and structure to the distribution and enhancement of cumulus clouds. $J$. Atmos. Sci, 37, 2051-2067.

Nutten, B., P. Amayenc, M. Chong, D. Hauser, F. Roux and J. Testud, 1979: The Ronsard radars: a versatile C-band dual Doppler facility. IEEE Trans. Geosci. Electron., GE-17, 281288.

Panofsky, H., 1973: Spectra of atmospheric variables in the boundary layer. Radio Sci., 4, 1101-1109.

Rabin, R., and D. S. Zrnić, 1980: Subsynoptic scale vertical wind revealed by dual-Doppler radar and VAD analysis. J. Atmos. Sci., 37, 644-654.

-, R. J. Doviak and A. Sundara-Rajan, 1982: Doppler radar observations of momentum flux in a cloudless convective layer with rolls. J. Atmos. Sci., 39, 851-863.

Reinking, R. F., R. J. Doviak and G. O. Gilmer, 1981: Clear air roll vortices and turbulent motions as detected with an airborne gust probe and dual-Doppler radar. J. Appl. Meteor., 20, 678685.

Ryan, B. F., and P. Lalousis, 1978: A one-dimensional time-dependent model for small cumulus. Quart. J. Roy. Meteor. Soc., 105, 615-628.

Sommeria, G., 1982: COPT 81: A field experiment designed for the study of dynamic and electrical activity of deep convection in continental tropical regions. Preprints Conf. on Cloud Physics, Chicago, Amer. Meteor. Soc., 580-583.

- , and J. W. Deardorff, 1977: Subgrid-scale condensation in models of nonprecipitating clouds. J. Atmos. Sci., 34, 344-355.

Testud, J., and M. Chong, 1983: Three-dimensional wind field analysis from dual-Doppler radar data. Part I: Filtering, interpolating and differentiating the raw data. J. Climate Appl. Meteor., 22, 1204-1215.

Turner, J. S., 1973: Buoyancy Effects in Fluids. Cambridge University Press, $367 \mathrm{pp}$.

Warner, J., 1973: The microstructure of cumulus clouds. Part IV: The effect on the droplet spectrum of mixing between cloud and environment. J. Atmos. Sci., 30, 256-261.

- , and J. W. Deardorff, 1967: Convection below cloud base. $J$. Atmos. Sci., 24, 374-382. 